\title{
Professional Development Strategies of English Teachers for Rural Primary and Middle Schools in Lifelong Education Perspective
}

\author{
Ji Meng ${ }^{a}$, Lifeng Wang ${ }^{b}$ \\ Teaching and Research Institute of Foreign Languages, Bohai University, Jinzhou, 121013, China \\ a511827658@qq.com, bbhdxwanglifeng@163.com
}

Keywords: lifelong education; rural primary and middle schools; English teachers; professional development strategies

\begin{abstract}
The professional level of English teachers has profound influence on English teaching. Only by continuously improving the professional level of English teachers can we achieve the goal of English teaching. Based on the analysis of the problems existing in the development of primary and middle English teachers in rural areas, this paper puts forward the strategies of English teachers' professional development in rural primary and middle schools from the perspective of lifelong education, and fundamentally resolves the professional development problems of English teachers in rural primary and middle schools to improve the professional and technical level of English teachers and English teaching effect. Theoretically to further enrich and supplement the existing basic education theory and methods, and practically for the school or the education department of decision-making behavior to provide a certain scientific reference.
\end{abstract}

\section{Introduction}

English as an international language by the people of the world attention and concern, and also in many countries as the official language. In the process of language learning, the professional development of teachers is very important to the reform of foreign language education, which directly affects the process and effect of students to learn foreign language. After years of rapid development, although most of the rural primary and middle schools are equipped with English teachers, but the professional quality of teachers is still a weak link in basic education, no fundamental change, there is a certain distance to the quality education requirements, and it is difficult to keep up with the 21st century socio-economic and educational development pace. The development of English teachers in the social environment is a continuous lifelong process. Lifelong learning is the magic weapon and source of teachers' ability to maintain their scientific and advanced nature, it is the way for teachers to obtain the latest knowledge, ability and quality and the only developmental way for contemporary teachers and students. It is particularly important to the poor professional quality of primary and middle school teachers in rural areas, which has become a very important and urgent subject for basic education worker to face.

English teachers professional development, can be understood as the professional growth of teachers or the inherent level of education and professionalism of teachers, as well as professional psychology of the continuous improvement and developmental process, which refers to the teacher in the entire professional education career, relying on professional organizations through their own continuous efforts to learn the professional skills of education, and gradually enhance the quality and self-cultivation to become a good English professional career growth. In the vast rural areas, due to the ideas, geographical environment, economy and culture, social development and other factors long-term constraints and influence. Primary and middle school English teachers generally low starting point, less training opportunities, backward education, knowledge base is weak, professional quality is not high, lack of educational and teaching ability, it is difficult to adapt to the new round of basic education curriculum reform and development needs. It is necessary to take the new curriculum reform as an opportunity to strengthen the construction of rural compulsory education teachers groups, to promote the professional development of English teachers, to narrow the gap between urban and rural areas, so as to improve the rural fundamental education quality. It 
is of great theoretical and practical significance to study the professional development of English teachers in rural primary and middle schools.

\section{Basic Theory on Professional Development of English Teachers for Rural Primary and Middle Schools}

The basic theory provides the basis for the research of the subject, including the theory on professional development of teachers, lifelong education theory, career development theory and adult learning theory.

(1) Teacher professional development theory. The professional development of teachers is the enrichment and skill of teachers 'professional knowledge, the persistence and pursuit of professional beliefs, the deep and positive emotion of professional emotion, the unique and outstanding teaching style, and the emphasis on teachers' inner professional accomplishment, affection and ability promotion. Teachers' professional development theory emphasizes on the consciousness and autonomy of work, the stage and dynamic of development. Based on the understanding of the professionalization of teachers, it is necessary to strengthen and develop the professional status of teachers, to train teachers in specialized training, to promote teachers' continuous learning, to improve professional accomplishment and innovation ability, to develop professional ability and teaching level.

(2) Lifelong education theory. The development peak of lifelong education theory in the early 20th century, with the progress of science and technology and knowledge extension, people are increasingly aware of the important role of education, more emphasis on the beginning of life to the end of the whole education process. The theory of lifelong education plays an important role in promoting the career development of teachers, as follows: emphasizing the comprehensive and coordinated development of human beings, requiring education to be diverse and flexible, emphasizing the integration and unification of education, emphasizing the organic integration of various education training, more democratization, the need to play the role of social resources, emphasizing the learner's subjectivity and leading role, attention to the use of modern information technology.

(3) Career development theory. From the beginning of the early 1950s, many scholars began to study career development problems, formed a series of theoretical doctrine in which Super's career development theory is the most representative, emphasizing the subjective and objective interaction, and thinks people are different. Career choice and adaptation is a continuous process, and career development process is plastic. Career development is divided into five stages: the growth period, the exploration period, the establishment period, the maintenance period and the recession period, and the later research put forward the spiral cycle development mode of life. Super emphasis on personal attention to the rule of career development, according to the development stage to arrange their own tasks with reasonable career development process, which make all stages can be on schedule.

(4) Adult learning theory. Refers to the combination of adult education in the guiding ideology and training learning theory to adult physiological and psychological characteristics, learning desire and system-based, summed up the specialized guidance for adult training education theory. This theory has its own unique, to fill the previous training model is mainly aimed at training children and beginners which is the establishment of this blank area, and training theory is another major breakthrough. The theory mainly combines the adult training, adult psychology, with the specificity of adult education to build adult learning model system.

\section{Existing Problems on Professional Development of English Teachers for Rural Primary and Middle Schools}

Through in-depth investigation and systematic analysis, it is concluded that there are many problems in the professional development of English teachers in rural primary and middle schools: the task of teaching is arduous, the contradiction between teaching and learning is prominent, the 
knowledge is narrow, the knowledge of other related subjects is lacking, the knowledge structure is single, lack of theoretical knowledge, lack of teaching ability, lack of teaching and research ability, lack of professional identity, lack of motivation in professional development , lack of overall professional development planning awareness, teacher evaluation is too single, teaching research and training opportunities are limited, emotional attitude values immature, lack of professional burnout, self-professional development awareness is not strong, teacher training and teaching work is not close, poor training effectiveness. The main questions are summarized as follows [1-3]:

(1) Lack of language practice opportunities, and language application ability is not strong. English language practice includes "listening practice, dialogue practice, reading practice and writing practice". In the course of daily English teaching and learning, English teachers must break through theoretical constraints, combine theory with practice, do theoretical practice, which is the practice of language. But most of the English teachers and students learn English knowledge only in the school environment, no foreign training opportunities, can not really communicate with the English-speaking countries, resulting in the teaching of teachers in their own business capacity is weak, and the language is too books. The Classroom teaching can not be better to guide students to appreciate the language charm, can not create an English classroom environment, and does not help improve students' English communication ability.

(2) Professional sense of identity is not strong, and lack of professional development awareness. Occupational identity refers to the individual's views on the goals, social values and other factors of the profession, and it is the psychological basis for trying to do their jobs and achieve the goals of the organization. Many rural primary and middle English teachers do not want to take root in rural education, hoping to regard teacher as a platform for better development, the work as a means of subsistence, lack of specific experience and sentiment for teaching and educating work. Many rural primary and middle English teachers, for their own professional development are recent and phased planning, lack of integrity and long-term planning, unfamiliar with the current professional development of the state. There is no long-term professional development goals, lack of a clear sense of self-learning and the improvement level of English desire.

(3) School leadership take seriously insufficiently, and teachers professional development support is lack of environment. Teacher development is the source of student development and school development. In the process of teacher professional development, the support of school leaders has a very important role. But many rural primary and middle school leaders, that the teacher's job is to do a good job teaching, the present existing English level is fully able to cope with daily teaching, there is no need to improve and develop. In addition, many rural primary and middle schools are in poor economic condition, educational investment and economic level do not match, the rural education of various infrastructure and modern teaching support means is scarce, the school training activities do not have rich resources, combined with a number of primary and middle English teachers less, it is difficult to organize teaching and research activities, and the lack of deep communication and interaction between teachers.

(4) Lack of targeted training content, and less self-learning time. Different rural primary and middle school English teachers, different educational background, and different levels of English, teaching problems also encounter in different, so the training content has different requirements. But the training is usually carried out for many teachers, the training process is also main theoretical courses, lack of targeted. Self-learning is an active learning behavior of the individual in the learning process. Maslow's theory of demand hierarchy shows that high-level demand is based on the premise that the basic needs are adequately meet. There are no changes in the number of English teachers in rural primary and middle schools, the number of teaching hours are too much, but also instruction and answer, work intensity is too large. Heavy work stress makes English teachers do not have time to learn and think about self-learning and self-development.

\section{Professional Development Strategies of English Teachers for Rural Primary and Middle Schools in Lifelong Education Perspective}

Strategy is to achieve a certain goal, which may develop a number of response programs according to the status quo and expected problems. According to the problems existing in the 
process of professional development of primary and middle English teachers in rural areas, this paper uses the theory of teacher professional development and lifelong education, combined with national policies and regulations and the relevant documents of educational authorities, draws lessons from the experience of typical developed countries, the professional development strategy of rural primary and middle school teachers in rural areas under the lifelong education is as follows [4-8]:

(1) Strengthen the construction of teachers, and improve the rural primary and middle school English teachers professional level. The construction of teachers' ranks is an important content of the construction of school, and it is the guarantee of sustainable development of education. "Outline of medium and long-term education innovation and development plan (2010-2020)" clearly pointed out that "with an emphasis on rural teachers, improve the overall quality of primary and middle school teachers. Innovative rural teachers to complement the mechanism to improve the system and policies to attract more talents for teaching". Education departments should continue to implement the rural compulsory education school teachers ad hoc job plans to increase the English graduates, especially the introduction of outstanding graduates, to attract English graduates to teach in rural areas. At the same time, rural primary and middle schools can also employ the top teaching teachers, to the school for reporting, lectures or flexible introduction as guest teachers. English major graduates and guest teachers, on the one hand can solve the problem of insufficient number of primary and middle school English teachers in rural areas, on the other hand can also lead other teachers to learn and apply advanced teaching ideas, help other teachers to improve their professional quality

(2) The establishment of urban and rural integration training network, explore the rural primary and middle English teachers to enhance the ability by new ways. Urban and rural economic development is imbalance, and the long-term implementation of education in the "city priority" value orientation, leading to urban and rural education development is not balanced. Lack of rural quality education resources, we must actively seek the support of urban quality resources, and the establishment of urban integration training network. Specific operations can have two kinds of programs: first, rural English teachers and urban English teachers together to participate in training, in the exchange process to learn from each other to jointly improve the level of English teaching; second, take "go out, please come in" to invite rural teachers in primary and middle schools to participate in the training of urban primary and middle school teachers to rural primary and middle schools on-site demonstration or seminars to help rural English teachers to establish a new curriculum to change the concept, to enhance the school, English professional knowledge and teaching and research ability, in order to transport the city's high-quality resources to rural areas, to guide the quality of rural teachers and to promote the urban and rural basic education balanced development.

(3) To create a good professional development environment, to guide primary and middle English teachers professional development lifelong planning. School is the main position of teacher professional development planning, to create a good development environment, to maximize the primary and middle English teachers to provide support conditions. First of all, solving the problems of teachers to learn and work, so that teachers are wholeheartedly into the teaching work, stimulate the motivation of teachers, arouse the enthusiasm of teachers, so that teachers have a sense of belonging and a sense of accomplishment; and then, the school need to open up the vision of teachers, build up exchange and research platform, and actively encourage the independence of teachers thinking and creativity, to stimulate teachers professional development potential for the stage of talent, so that teachers in teaching practice gradually understand new ideas and new methods; finally, to guide primary and middle English teachers to make the development of self-professional development plan, which can be divided into short-term planning, medium-term planning and long-term planning to determine the key factors in the implementation of the plan, in the implementation process according to the conditions and changes, continue to adjust and revise the plan to adapt to life professional development needs. 
(4) Enhance self-development awareness, the formation of perseverance and guiding ideology of lifelong learning. Teachers themselves are the main body of professional development, to take the initiative according to the actual situation, continue to create conditions for professional development. To explore ways to achieve professional development goals, to actively enrich the knowledge and improve teaching skills, and new knowledge and new skills applied to the daily English teaching work. In the course of practice, the past development process, the current state of development and possible future development level, combined with the current level of future development direction, with the future development goals dominate the current action. Lifelong learning refers to the process of adapting to social development and achieving the needs of individual development, throughout the life of people, continuous learning process. In the construction of learning society today, teachers' lifelong learning is particularly important. The new curriculum reform emphasizes quality education, requires teachers to set up lifelong learning ideas, seize this opportunity, learn from multiple channels, learn to enhance professional accomplishment, enrich the theoretical connotation, and actively participate in the reform and practice of English education research, to grow into a good English teacher.

(5) Give full play to the advantages of information technology and construct the lifelong learning platform for primary and middle school English teachers. In the information age, the application of information technology has led to profound changes in teaching ideas, teaching concepts, teaching contents and teaching methods, providing a wider learning platform, richer resources sharing space and further development of the stage, to promote teacher growth and the effective way of new curriculum reform. The concrete role includes three aspects: first, to reform the concept of professional development of teachers to enhance the quality of teaching and research ability of teachers to update the knowledge structure of teachers to promote teacher teaching innovation; second, to promote the role of teachers to become information creators of creative activities; third, the improvement of teacher management and evaluation, innovation and evaluation of teacher means and content, strengthen the standard of teacher management, and promote the further advance of education. The use of information technology to build a relatively independent English language interactive platform to build an open learning environment, to achieve the full integration of resources, to carry out self-learning, continue to draw on cutting-edge knowledge, and promote the continuous improvement of English professional level.

\section{Conclusion}

The main purpose of teacher professional development is to improve the teachers' own quality and lifelong learning ability, keep pace with the time, keep innovating, improve teaching quality and improve teaching effect. The professional level of English teachers has a far-reaching impact on primary and middle English teaching. Only by continuously improving the professional level of English teachers can we achieve the teaching objectives of primary and middle English. The purpose of this paper is to study the new theories and new methods to promote the professional development of English teachers in rural primary and middle schools, to solve the key problems in the development of English teachers in rural primary and middle schools, and to improve their professional and technical level for rural primary and middle school teachers guidance, for the education management and rural primary and middle schools to develop English teacher improvement planning, to improve the English education curriculum system to provide a theoretical basis, to promote the quality of rural primary and secondary English teachers to improve the overall. Theoretically further enrich and supplement the existing basic education theory and methods, in practice, for the school or the education department of decision-making behavior to provide a certain scientific reference.

\section{Acknowledgement}

This work is supported by 2015 annual "Twelfth Five Year" Education and Science Planning Project in Liaoning Province (JG15CB164): Professional Development Strategies of English 
Teachers for Rural Primary and Middle Schools in Lifelong Education Perspective.

\section{References}

[1] Y. Xiong, Z. Yuan, "The Construction and Development of Professional Development Community of Primary School English Teachers," Theory and Practice of Education, vol. 34, no. 6, pp. 37-38, 2014.

[2] S. Wu, "Current Situation of Rural School Teachers' Professional Development and Counter Measures," Master's degree of Guangxi Teachers Education University, 2014.

[3] X. S. Long, "The application of new media resources in college English teaching," Overseas English, vol. 17, no. 21, pp. 38-39, 2016.

[4] D. Y. Liu, "On the professional development of English teachers in primary and secondary schools," http://old.pep.com.cn/ce/czyy/zhuanji/xygrzj/cuiluan/clll/904795.htm, 2017-2-1.

[5] Daniella Molle, "Facilitating professional development for teachers of English language learners," Teaching and Teacher Education, vol. 29, no. 2, pp. 197-207, 2013.

[6] T. Martijn Willemse, Geert ten Dam, Femke Geijsel, et al., "Fostering teachers' professional development for citizenship education," Teaching and Teacher Education, vol. 49, no. 1, pp. 118-127, 2013.

[7] Gabriella Aleandri, Luca Refrigeri, "Lifelong Education and Training of Teacher and Development of Human Capital," Procedia - Social and Behavioral Sciences, vol. 136, no. 9, pp. 542-548, 2014.

[8] X. Y. Lin, "The Inspiration of 'Career Management Theory' to Colleges Teacher Professional Development," Teacher Education Forum, vol. 28, no. 7, pp. 66-70, 2015. 